\title{
OS USOS DO CONCEITO DE "INDÚSTRIA CULTURAL" NA TEORIA DA COMUNICAÇÃO: UM ESTUDO DE CINCO REVISTAS ACADÊMICAS (2004-2008)
}

\author{
THE “CULTURAL INDUSTRY” CONCEPT IN COMMUNICATION THEORY:
}

A SURVEY OF FIVE ACADEMIC JOURNALS (2004-2008)

LOS USOS DEL CONCEPTO DE “INDUSTRIA CULTURALE” EN LA

TEORIA DE LA COMMUNICACIÓN: UNA INVESTIGACIÓN DE CINCO

PERIODICOS CIENTIFICOS (2004-2008)

\author{
Luís Mauro Sá Martino \\ Professor da Faculdade Cásper Líbero \\ lmsamartino@gmail.com \\ Maysa Ciarlariello Cunha Rodrigues \\ Mestranda em Sociologia - Universidade de São Paulo \\ maysa.ccr@gmail.com
}

\section{Resumo}

Este artigo estuda a presença e as apropriações do conceito de "indústria cultural" na Teoria da Comunicação contemporânea, tomando como base artigos publicados nos cinco últimos anos nas revistas Comunicação \& Educação, Comunicação \& Sociedade, Comunicação, Mídia \& Consumo, Famecos e Galáxia. Foi possível delinear três aspectos da questão: (a) O conceito é mencionado em cerca de 5\% dos artigos analisados; (b) $\mathrm{O}$ uso varia da simples menção até uma discussão mais profunda; (c) Em alguns casos, mesmo quando não mencionado, é possível identificar o conceito como referência. Isso sugere que a noção de "indústria cultural" se manteve pertinente apesar das mudanças sociais e tecnológicas na própria comunicação.

Palavras-chave: Teoria da Comunicação; Escola de Frankfurt; Indústria Cultural

\section{Abstract}

This papers outlines the presence and uses of the "Culture Industry" concept in contemporary Communication Theory. It focuses on articles published in the best listed Brazilian Media and Communication academic journals in the last five years. The results show at least three

Esta obra está licenciada sob uma Licença Creative Commons 
main aspects: (a) the concept is mentioned in nearly 5\% of the articles; (b) However, there is a wide range of uses, from a single mention to a detailed discusstion; (c) Even when it is not mentioned, there seems to be an 'echoe' of the concept in some articles. It suggests that "culture industry" is still a conceptual resource to understand contemporary communication.

Keywords: Communication Theory; Frankfurt School; Epistemology.

\section{Resúmen}

Este trabajo estudia la presencia y los usos del concepto de "industria cultural" en la teoría de la comunicación contemporánea, basado en artículos publicados en los últimos cinco años en las revistas Comunicación y Educación, Comunicación y Sociedad, Comunicación, Medios y Consumo, Galaxia y Famecos. Es posible destacar tres principales resultados de la investigación: (a) El concepto se menciona en un 5\% de los artículos analizados; (b) El uso varía de palabras sencillas para un debate más profundo, (c) En algunos casos, el concepto no se menciona, aunque es posible identificar su presencia. Esto sugiere que la noción de "industria cultural" sigue siendo pertinente a pesar de los cambios tecnológicos y sociales en la propia comunicación.

Palabras-clave: Teoria de la Comunicación; Epistemología; Teoria Crítica.

\section{INTRODUÇÃO}

Qual é o espaço do conceito de "indústria cultural” nas pesquisas atuais sobre comunicação? Este texto tem como objetivo delinear uma resposta possível a essa pergunta a partir do estudo de artigos publicados em cinco das principais revistas acadêmicas da área Comunicação \& Educação; Comunicação \& Sociedade; Comunicação, Mídia \& Consumo; Famecos e Galáxia - nos últimos cinco anos, procurando verificar, de um lado, a presença do conceito e, de outro, as modalidades de sua utilização.

Até que ponto o conceito, formulado na década de 1940 por Max Horkheimer e Theodor Adorno, ainda encontra acolhida na produção brasileira contemporânea? Busca-se verificar se a ideia ainda é uma categoria de análise relevante no campo e, em caso positivo, de qual maneira está se dando seu uso. Não é o objetivo aqui fazer uma genealogia do conceito e de seu desenvolvimento, tampouco uma história de sua apropriação pela área. A intenção é delinear alguns aspectos de sua apropriação atual, tal como apresentada nos artigos analisados.

Uma das premissas que levou à formulação deste trabalho é a percepção de uma certa ambigüidade no que diz respeito à presença e ao uso do conceito de "indústria cultural" nos 
estudos de comunicação, apontada, entre outros, por Venício Lima (2001) e Francisco Rüdiger (1998).

De um lado, nota-se a presença do tópico em quase todos os livros intitulados "Teoria da Comunicação" disponíveis para o leitor brasileiro (Martino, 2007; 2009). Por outro, o conceito parece ter perdido seu espaço como elemento de compreensão dos fenômenos comunicacionais em primeiro lugar, pelas novas propostas teóricas do chamado "paradigma das Mediações" e pelos novos ambientes da internet que, de alguma maneira, evidenciaria uma certa impossibilidade de se usar as categorias de análise que dão base teórica ao conceito de "indústria cultural", a saber, a noção de uma "massa" a ser atingida pelos "meios de comunicação de massa" (Scolari, 2008). Qual seria o espaço do conceito de "indústria cultural" nesse cenário?

Em um quadro mais amplo, parte-se da premissa que a presença, ausência e utilizações de um conceito são um indício que permite delinear as fronteiras epistemológicas de uma área. Nesse cenário, uma outra questão, presente nos debates epistemológicos vem à tona: até que ponto a apropriação da idéia de "indústria cultural" pela área da comunicação a torna, efetivamente, uma teoria $d a$ comunicação? Seria possível lembrar que mesmo no debate epistemológico nota-se a ausência de um consenso a respeito do que é, de fato, uma teoria da comunicação - nesse caso, o estudo dos usos do conceito de indústria cultural oferece uma perspectiva, ao menos parcial, para se compreender algumas das dinâmicas conceituais da Comunicação (Martino, L. C., 2001; Martino, L. M., 2007).Mais do que observar uma presença numérica, embora esse dado tenha relevância como um indicativo da presença, o objetivo é verificar as modalidades de utilizações do conceito nos artigos analisados. Os temas deste texto se situam em um quadro de dúvidas epistemológicas com as quais os autores vêm lidando em outros espaços (Rodrigues, 2009; Martino, 2008; 2010).

A escolha metodológica de trabalhar com revistas acadêmicas, não com teses ou com outros tipos de expressões acadêmicas, deve-se à projeção das publicações, constituindo a principal forma de divulgação dos trabalhos científicos na área. As revistas foram definidas conforme estivessem classificadas com o conceito “A” pelo índice Qualis, da Coordenação de Aperfeiçoamento de Pessoal de Nível Superior, ano base 2006, e ter vínculo universitário direto, ou seja, não ser atrelado a uma associação ou entidade de pesquisa. Essas definições geraram o corpus com as cinco revistas. 
A escolha seguinte foi analisar todas as edições entre 2004 e 2008 das revistas selecionadas. Foram separados os artigos que citassem "Adorno" ou "Horkheimer" nominalmente em bibliografia, em um total de 28 textos.

Cada um dos artigos selecionados foi analisado, dando-se ênfase a forma como cada um deles se apropriou do conceito "indústria cultural”: seria apenas citado como referência no artigo ou estaria sendo de fato discutido a partir de uma negação, reafirmação ou revisão? Além disso, a análise observou como cada um dos artigos se manifestava sobre a mudança na esfera da tecnologia teria alterado o modelo de comunicação unidirecional presente no conceito "indústria cultural".

\section{O CONTEXTO DOS USOS DO CONCEITO}

A apropriação do conceito de "indústria cultural" pelos estudos brasileiros de comunicação certamente merece uma genealogia que escapa aos limites deste trabalho. No entanto, parece necessário pontuar alguns momentos particularmente importantes como maneira de identificar algumas continuidades e/ou rupturas com o momento atual examinado neste texto.

A apropriação e difusão das idéias da Escola de Frankfurt no Brasil ainda está por ser escrita, mas vale observar que, aparentemente, ela tem início no final dos anos 1960. Uma tradução do artigo "A obra de arte na época de sua reprodutibilidade técnica" aparece em um livro organizado por José Lino Grunenwald, A idéia de cinema, em 1968. No ano seguinte, o texto aparece em outra tradução na revista Civilização Brasileira. A discussão sobre arte e cultura de massa também está presente em outros trabalhos pioneiros, sobretudo uma série de artigos publicados por Ferreira Gullar na mesma revista, sem mencionar a primeira edição brasileira de Apocalípticos e Integrados, de Umberto Eco, ainda em 1967.

O capítulo “A Indústria Cultural”, do livro Dialética do Esclarecimento, é publicado separadamente na coletânea Teoria da Cultura de Massa, organizado por Luiz Costa Lima, em 1969. Finalmente, o artigo "A indústria cultural”, de Adorno, foi publicado no Brasil no livro Comunicação e Indústria Cultural, organizado por Gabriel Cohn. Trata-se de uma palestra radiofônica de Adorno, no qual são explicitadas algumas distinções fundamentais no tema - a primeira delas, uma diferenciação entre os conceitos "cultura de massa" e "indústria cultural". Na primeira expressão estaria incluída a concepção de uma cultura popular 
espontânea. "Indústria cultural", muito pelo contrário, diria respeito à intencionalidade de "produtos adaptados para o consumo das massas".

É relevante salientar que "indústria cultural" não foi um conceito desenvolvido para explicar o processo de comunicação, mas nasceu em uma tradição que transita entre a Filosofia e a Sociologia. Barbara Freitag (1990:12) afirma em A Teoria Critica ontem e hoje que "provavelmente a teoria crítica da escola de Frankfurt tornou-se mais conhecida no mundo inteiro pela sua crítica à cultura de massa que pelos seus demais trabalhos em outros campos do saber". As possibilidades atuais de operacionalização do conceito para a compreensão da sociedade contemporânea vem sendo ressaltada por pesquisadores como Cohn (1998) e Coelho (2008). No entanto, por outro lado, é possível encontrar também problematizações como a de Francisco Rüdiger (1998:13):

\begin{abstract}
Passado o período em que esteve na moda e - mal ou bem - chegou a se revelar um estímulo produtivo na pesquisa, a crítica à indústria cultural foi perdendo seu charme e a compreensão de seu pensamento passou a ser dada como encerrada com a leitura superficial de um ou outro texto. Os frankfurtianos passaram a ser classificados como apocalípticos, de acordo com uma distinção bastante popularizada entre nós e que, válida - no máximo - como resumo de uma trama urdida de maneira muito mais complexa, terminou se tornando um esquema reificado e um código de contato entre os pesquisadores da comunicação.
\end{abstract}

\title{
2. AS VARIANTES NO USO DE "INDÚSTRIA CULTURAL"
}

O corpus selecionado ofereceu uma variedade de formas de apropriação do conceito “indústria cultural”. Dentre a multiplicidade de artigos é possível notar tanto proximidades quanto divergências. Alguns artigos realizam menções claras e explícitas ao conceito, seguidas de definições do que seria "indústria cultural", atestando assim a ligação dessa menção com o conceito de Adorno e Horkheimer e se apropriando do conceito para explicar determinado fenômeno. Em outros textos, a menção oferece menos elementos que permitam ligar a expressão "indústria cultural” ás implicações do conceito frankfurtiano. Em outros trabalhos, apesar de Adorno e/ou Horkheimer serem citados em bibliografia, não há sequer menção ao conceito.

Em alguns artigos são expressões como "Adorno”, “Adorno e Horkheimer”, “Teoria Crítica", "Autores da Teoria Crítica", "Frankfurtianos", "Dialética do Esclarecimento". 
"Apocalípticos", "Escola de Frankfurt", "Sociologia Crítica" que evidenciam a menção dos autores ao conceito em questão.

Embora o que se apresente adiante seja uma divisão, vale ressaltar de saída que essa cisão no que tange aos usos procura apenas um delineamento, sem nenhuma intenção propriamente classificatória, o que de alguma maneira significaria congelar os conceitos utilizados. Ao contrário, a imagem mais próxima da realidade seria pensada em termos de um continuиm que vai da apropriação e discussão do conceito, em um extremo, até a simples menção sem maiores discussões, em outro. As formas de abordagem são tantas quanto o número de artigos, uma vez que cada autor faz uso do conceito de acordo com sua proposta específica.

Seria possível, feita essa ressalva, se pensar em três principais usos nos artigos que explicitam o conceito. Em um primeiro caso, há aqueles se caracterizaram por uma discussão mais clara de suas implicações, tanto no sentido de negá-lo parcial ou totalmente quanto no sentido de reafirmá-lo. Em seguida, a presença referencial do conceito, ou seja, "indústria cultural" (seja citada nominalmente ou através de outras expressões indicativas, como apresentadas acima), tende a aparecer antes como uma citação secundária do que como assunto principal nesses textos. Finalmente, artigos nos quais o conceito não aparece nominalmente, mas nos quais há elementos que poderiam permitir alguma forma de diálogo com o conceito. No que se segue, serão discutidos brevemente os textos analisados.

\subsection{O conceito como elemento de análise e discussão}

O primeiro grupo de análises que distinguimos traz aqueles artigos que oferecem evidências de um diálogo mais claro com os textos básicos de Adorno e Horkheimer, sem a necessidade, entretanto, de se direcionarem apenas nesse viés. Estarão excluídos dessa categoria os artigos em que a presença do conceito parece ser mera citação, sem que o texto dialogue de fato com as idéias dos autores.

No artigo "Comunicação e arte: o experimento sociológico de Brecht” (Frederico, 2008), apesar do conceito não ser apresentado, o diálogo com "indústria cultural" se delineia quando o autor expõe o embate intelectual entre Brecht e Adorno: para Adorno o cinema seria um produto da "indústria cultural", enquanto que para Brecht poderia ser considerado uma 
obra de arte. Nos artigos "Interfaces: Michel Maffesoli, teórico da comunicação" (Silva, 2004), "A política na TV de ficção" (Silva, 2005) e "Videotrash: o youtube e a cultura do "spoof" na internet" (Felinto, 2008) a apropriação do conceito "indústria cultural" parece implicar em uma negação.

Em “Interfaces: Michel Maffesoli, teórico da comunicação", Juremir Machado da Silva toma as idéias de Maffesoli como centro de seu artigo. O conceito, embora não discutido integralmente, dialoga com o texto quando o autor opõe a noção de "indústria cultural", dos autores da Escola de Frankfurt à noção proposta por Maffesoli, para quem a comunicação não seria uma ferramenta de dominação, mas sim uma forma de socialização por natureza.

Em "A política na TV de ficção" o mesmo autor explicita alguns aspectos inerentes ao conceito e se opõe à ideia de que a "indústria cultural" seria um poderoso mecanismo ideológico capaz de tornar a massa passiva. Argumenta que a televisão no Brasil oferece espaço para "pluralidade" e para discussões pedagógicas e educativas, especialmente através de novelas (como "Pantanal", exibida em 1989 pela extinta TV Manchete). Paralelamente, enfatiza a questão da recepção, já que os indivíduos "neutralizariam" e "interpretariam" as mensagens cotidianamente.

Erick Felinto inicia "Videotrash: o youtube e a cultura do "spoof" na internet" apontando para o fenômeno atual de "relativização de padrões e valores culturais", que implicaria ao mesmo tempo em uma maior liberdade e em um vazio em relação aos valores perdidos. Essa relativização alteraria o paradigma defendido por Adorno e Horkheimer de que de um lado haveria as obras de arte legítimas e do outro o "lixo cultural" produzido pela “indústria cultural”, que poderia ser excluído sem fazer falta. Para o autor, o que de fato teria ocorrido é que esse "lixo cultural" teria encontrado na internet um campo propício para se perpetuar a partir de um gigantesco espaço de armazenamento a baixos custos e de um novo valor social (a partir da cultura do "spoof"). O autor parece questionar até que ponto "indústria cultural" dá conta de fenômenos como a cultura do "spoof", apontando para a necessidade de novas hipóteses que analisem as produções do ciberespaço segundo outros critérios além do seu conteúdo.

O artigo "A teoria do valor de Marx e a educação do gosto", de Marco Schneider (2006), faz uso do conceito "indústria cultural" para explicar o fenômeno da formação do gosto pessoal. Há menção textual ao conceito neste artigo que se afirma com o objetivo 
"atualizar a perspectiva crítica fundada por Adorno e Horkheimer na Dialética do Esclarecimento, em que foi cunhado o termo indústria cultural e onde se começou a problematizar as consequências sociais da mercantilizarão da cultural (...)”. Schneider (2006) e Silva (2005) se aproximam, pois em “A teoria do valor de Marx e a educação do gosto" há certa crítica ao conceito "indústria cultural" a partir do argumento de que as especificidades na recepção seriam ignoradas por Adorno e Horkheimer, que considerariam o receptor passivo.

\subsection{As referências oblíquas ao conceito}

Em um segundo espaço agrupamos artigos nos quais a apropriação do conceito "indústria cultural” ocorre de forma menos explícita no texto. Em parte significativa desses artigos o conceito não passa de uma referência bibliográfica, de forma que não há indicações, no texto, de sua presença. Os artigos deste grupo se assentam, portanto, num continuum entre artigos cujo conceito não passa de referência bibliográfica e outros, cujo diálogo se estabelece, mesmo que de forma mais indireta do que no item anterior.

Em "Introdução à dromocracia cibercultural: contextualização sociodromologica da violência invisível da técnica e da civilização mediática avançada" (Trivinho, 2005), o autor faz uso de noções que podem ser aproximadas das usadas por Adorno e Horkheimer (tempo livre e racionalização da técnica). Apesar disso, a menção a "indústria cultural" não é explicita.

No artigo "Juízo de valor e o valor dos juízos: estratégias de valoração na prática do samba" (Trotta, 2007) o conceito "indústria cultural" aparece indiretamente a partir da expressão "estilo apocalíptico de Adorno e Horkheimer". O autor afirma que algumas pessoas tenderiam desqualificar o ritmo pagode afirmando que esse tipo musical corresponde a algo artificialmente produzido por uma indústria. De resto, o texto não menciona o conceito, mas faz uma abordagem diferente da questão do valor de um produto musical (pensando nas estratégias de valorização).

O mesmo ocorre nos artigos "Comunicação e espaço público" (Pádua, 2004) e "Tecnologias de comunicação, entretenimento e competências cognitivas na cibercultura" (Régis, 2007), em que evidências sugerem uma crítica ao conceito, mas de maneira mais tangencial, uma vez que implícitas a partir da sugestão de outras perspectivas teóricas 
incompatíveis com a lógica inerente ao conceito "indústria cultural". Nesse mesmo sentido, em "Os leilões virtuais e a dimensão cultural da formação do valor econômico" (Vouga, 2008), apesar de haver citação ao conceito, o diálogo, e uma certa negação ao conceito, são indiretos. Vouga chama atenção para formas não óbvias de formação de valor econômico, afirmando que explicações como a da Teoria Crítica não dariam conta esses fenômenos.

“Comunicação e espaço público" (Pádua, 2004) também parece estabelecer uma relação de negação com conceito, pelo menos no momento em que critica a "Sociologia da Comunicação" e em que afirma que a perspectiva frankfurtiana ignoraria as especificidades no momento de recepção. Essa mesma crítica sobre a questão da recepção está presente em “Copa do mundo no Brasil: a dimensão histórica de um produto midiático" (Gastaldo, 2004).

No que diz respeito ao uso do conceito de forma mais referencial, alguns artigos são exemplares. Dentre eles, destaca-se "O cinema e a formação do docente: um diálogo sobre as questões de gênero" (Siqueira, Oliveira \& Braga, 2005) em que as autoras discutem a falta de atenção para as questões de gênero e de sexualidade na formação dos docentes e evocam a potencialidade dos meios de comunicação de massa para discutir tais questões. O conceito "indústria cultural” é explicitado como um "aparato para homogeneização e padronização das consciências e das visões de mundo".

Em outros artigos, o conceito é brevemente debatido. Em "Copa do mundo no Brasil: a dimensão histórica de um produto midiático" (Gastaldo, 2004), "indústria cultural” aparece de forma referencial e, discutindo a ideia de uma "recepção passiva", parece preferir a noção gramsciana de "hegemonia"). Algo semelhante ocorre em "Comunicação e espaço público" (Pádua, 2004). A autora primeiro reitera o conceito e em seguida realiza uma discussão crítica. Em "Cultura, consumo e estereótipos: significações de estudantes do curso de educação artística" (Ormezzano et alli, 2007) também pode-se notar um uso breve de “indústria cultural”, inclusive mesclado ao conceito "mass mídia".

\subsection{A ausência significativa do conceito}

Nesse grupo foram reunidos os artigos que, apesar de citarem Adorno e/ou Horkheimer em bibliografia, não evidenciam uma apropriação do conceito "indústria cultural". São eles "O sonho acabou? O governo Lula nos principais jornais italianos" (Dalpiaz, 2006), “Alteridade, corpo e morte no cyberspace: cicatrizes de um hipercrime na 
epifania do virtual" (Trivinho, 2004), “A condição transpolítica da cibercultura” (Trivinho, 2006), “Thomas Mann's Death in Venice: Visconti's film and Britten's opera” (Hess-Luttich, 2004), "Destruição e reconfiguração do corpo na publicidade mundial dos anos 90" (Saflate, 2004), "Propaganda, a arte de gerar descrédito" (Maman, 2008), "Por uma dialética da metamorfose: o novo público e o museu caleidoscópico" (Ferreira \& Moraes, 2007), "Clube da Luta: fábula anarquista pós-moderna sobre a dialética entre a civilização e a barbárie" (Costa \& Pimentel, 2006).

As seis primeiras análises desenvolvidas neste item sugerem que os artigos discutidos não apresentam nenhuma menção ao conceito "indústria cultural". Já em "Por uma dialética da metamorfose: o novo público e o museu caleidoscópico" (Ferreira \& Moraes, 2007), é possível sugerir uma evidência de diálogo indireto, a partir da posição favorável dos autores em relação às novas tecnologias que iria contra as proposições de Adorno e Horkheimer.

“Clube da Luta: fábula anarquista pós-moderna sobre a dialética entre a civilização e a barbárie", (Costa \& Pimentel, 2006) merece uma atenção especial dentre os artigos. Apesar de não haver menção explicita a "indústria cultural", o artigo que analisa o filme Clube da Luta proporciona uma reflexão sobre as idéias de Adorno e Horkheimer através de uma história ficcional. O desespero no qual o protagonista se encontra teria sua raiz na prisão da vida regida pelos processos de produção e de consumo, de forma que o trabalho e as compras gerariam a lógica opressora da vida contemporânea. No artigo "Art and Mass Culture" Horkheimer (1972) fala sobre o estado de desespero e de infelicidade o qual a humanidade estaria mergulhada ao ter sua vida privada transformada em extensão do trabalho, servindo para o consumo ou para preparação para o momento da labuta. Na Dialética do Esclarecimento, Adorno e Horkheimer (1985) definem o homem moderno como um eterno consumidor sujeito a escravização da "indústria cultural". No filme, o protagonista é um consumidor inveterado, que busca estabelecer sua inserção na sociedade e sua personalidade através desse consumo.

\section{DELINEAMENTOS FINAIS}

A leitura dos artigos do corpus chama atenção para uma espécie de paradoxo na presença do conceito: embora ele seja citado nos textos selecionados e nos livros de Teoria da 
Comunicação (Martino, 2008), o que poderia ser pensado como um indício de seu uso no campo da comunicação, nota-se uma certa tendência para um tratamento oblíquo do tema.

Uma primeira consideração é a permanência do conceito. Dentre os textos analisados, 28 faziam menção textual ao conceito "indústria cultural”, seja através de um diálogo propriamente dito ou, pelo menos através de uma citação. De antemão, esses dados permitem argumentar que, independentemente da forma como estiver sendo apresentando, o conceito está presente nos estudos de Comunicação.

Mas como interpretar essa presença? Se o olhar incidir sobre os números levando em conta o uso, seria possível dizer que apenas cinco artigos, dentre sessenta números, efetivamente discutem o conceito. Mas isso não seria ignorar que, por outro lado, vinte e sete artigos dialogam, ainda que indiretamente, com Adorno e Horkheimer? Seria o caso de mencionar, com o risco do paradoxo, uma "ausência significativa" ou uma "presença silenciosa" desses estudos no campo acadêmico, ressaltando uma presença que em alguns casos parece ser apenas nominal?

O passo decorrente é a indagação das formas pelas quais o conceito foi apropriado nos artigos. Dentre textos, é notável a ausência de artigos que discutam exclusivamente o conceito. Nenhum texto parece se debruçar sobre a teoria de Adorno e Horkheimer de forma profunda, com exceção da ambigüidade verificada em "Clube da Luta: fábula anarquista pósmoderna sobre a dialética entre a civilização e a barbárie" (Costa \& Pimentel, 2006), que apesar de não citar textualmente o conceito, inevitavelmente interpela o leitor familiarizado com "indústria cultural".

A partir dessa constatação, este trabalho se aproxima de uma das proposições de Francisco Rüdiger (1998), para quem o conceito teria sido tratado com demasiada simplificação. O autor chama atenção para o esvaziamento do sentido crítico de "indústria cultural", que muitas vezes é apresentado sem que fique claro até que ponto contém a complexidade de implicações atribuídas por Adorno e Horkheimer. De fato, em nenhum dos artigos estudados foi encontrado um panorama mais aprofundado do que significaria “indústria cultural”. Rüdiger usa a expressão "referência bibliográfica obrigatória" para definir os usos contemporâneos do conceito. A paradoxal idéia do autor parece se confirmar com as investigações desse trabalho.

Ademais, a análise dos artigos chama atenção uma relativa omissão a questão proposta sobre a validade de "indústria cultural" no contexto atual. Os quatro artigos que de certa 
forma se aproximaram dessa inquietação - "Videotrash: o youtube e a cultura do "spoof" na internet”, de Erick Felinto (2008); “Tecnologias de comunicação, entretenimento e competências cognitivas na cibercultura, de Fátima Régis (2007); "Por uma dialética da metamorfose: o novo público e o museu caleidoscópico", de Christine Ferreira e Marcelo Jacques de Moraes (2007) e "A teoria do valor de Marx e a educação do gosto", de Marco Schneider (2006) - apenas o fizeram de maneira parcial, conforme apresentado nas análises.

Há pouca discussão a respeito da validade epistemológica nem do conceito nem dos elementos nem de sua base conceitual e empírica. Também não é discutida a pertinência do conceito face às transformações sociais relacionadas às tecnologias de comunicação, da mesma forma que não se questiona a possível permanência das condições sociais nas quais esse discurso teórico foi formulado.

A partir desses argumentos, talvez se delineie uma revisão do conceito "indústria cultural" que leve em conta o cenário atual, um mapeamento de alguns elementos prévios para essa complexa investigação não poderia ignorar alguns pontos sugeridos pelos artigos analisados como o barateamento na emissão de mensagens; a ampliação de espaço virtual para armazenamento de informações; os novos produtos midiáticos e o questionamento sobre o papel que a os "receptores" poderiam assumir na atualidade por intermédio das tecnologias de mídia.

\section{REFERÊNCIAS}

ADORNO, T. A indústria cultural. In. COHN, G. Comunicação e Indústria Cultural. São Paulo; Nacional, 1971.

ADORNO, T. e HORCKHEIMER, M. Dialética do Esclarecimento. Rio de Janeiro: Sahar, 1985.

APONTE, J. Marlyn, loa intelectuales e La industria. Famecos. Porto Alegre, Volume 1, Número 34, 50-58, 2007.

AZZI, C. \& MORAES, M. Por uma dialética da metamorfose: o novo público e o museu caledoscópico. Galáxia, São Paulo, Volume 7, Número 13, 89-99, 2007.

BOLLOS, L. A música no jornal: recepção crítica do fenômeno bossa nova e implicações na cultura brasileira. Comunicação e Sociedade, São Paulo, 46, 2006.

BOURDIEU, P. Questões de Sociologia. Rio de Janeiro; Marco Zero, 1983. 
CASTRO, A. L. Corpo, consumo e mídia. Comunicação, Mídia e Consumo. São Paulo, Volume 1, Número 1, 17-32, 2004.

CASTRO, G. Clube da Luta: fábula anarquista pós-moderna sobre a dialética entre a civilização e a barbárie. Galáxia, São Paulo, Volume 6, Número 11, 57-71, 2006.

COELHO, C. N. P. Teoria crítica e ideologia na comunicação contemporânea: atualidade da Escola de Frankfurt e de Gramsci. Líbero, v. 11, p. 79-86, 2008.

COHN, G. A atualidade do conceito de Indústria Cultural. In: MOREIRA, A. (org). Sociedade Global. Petrópolis: Vozes, 1998.

DALPIAZ, J. O sonho acabou? O governo Lula nos principais jornais italianos. Famecos. Porto Alegre, Volume 1, Número 31, 70-78, 2006.

DURÃO, F., ZUIN, A.; VAZ, A. (orgs). A indústria cultural hoje. São Paulo; Boitempo, 2008.

FELITO, E. Videotrash: o youtube e a cultura do "spoof" na internet. Galáxia. São Paulo, Volume 8, Número 16, 33-42, 2008.

FERNANDES, F. Elementos da Sociologia Teórica. São Paulo: Edusp, 1970.

FREDERICO, C. Comunicação e arte: o experimento sociológico de Brecht. Comunicação \& Educação, São Paulo, Ano 13, Número 3, Página 13-19, 2008.

FREIRE FILHO, J. Notas históricas sobre o conceito de qualidade na crítica televisual brasileira. Galáxia, São Paulo, Volume 4, Número 7, 85-111, 2004.

FREITAG, B. A Teoria Crítica ontem e hoje. São Paulo; Brasilense, 1990.

GASTALDO, E. Copa do mundo no Brasil: a dimensão histórica de um produto midiático. Comunicação \& Sociedade, São Paulo, Volume 41, 2004.

HESS-LUTTICH, E. W. B. Thomas Mann's Death in Veneci: Visconti's film and Britten’s opera. Galáxia, São Paulo, Volume 4, Número 8, 73-100, 2004.

HORCKHEIMER, M. Critical Theory. New York; Continuum, 1972.

JAY, M. A imaginação dialética: História da Escola de Frankfurt e do Instituto de Pesquisas Sociais, 1923-1950. Rio de Janeiro: Contraponto, 2008.

LAGE, N. A comunicação decepcionante. Observatório da Imprensa.

<http://www.observatoriodaimprensa.com.br/artigos/jd230420031.htm> Acesso no dia 22 de outubro de 2009, às 18:32.

LIMA, V. Mídia, Teoria e Política. São Paulo: Perseu Abramo, 2001. 
MAMAN, A. Propaganda, a arte de gerar descrédito. Comunicação \& Educação, São Paulo, Ano 13, Número 3, Página 81-89, 2008.

MARTINO, L. C. Epistemologia da Comunicação. In. VVAA. O campo da comunicação. Recife, UFPE, 2001.

MARTINO, L. M. A ilusão teórica no campo da comunicação. Revista FAMECOS, Vol. 8, no. 36, 2008.

MARTINO, L. M. O que foi teoria da comunicação? Um estudo da gênese do campo (1964-1986). Trabalho apresentado no XXXIII Congresso da Intercom - Caxias do Sul, 4 a 7 de setembro de 2010.

MARTINO, L. M. Teoria da Comunicação. Petrópolis, Vozes, 2009.

MARX, K. O capital. Rio de Janeiro: Civilização Brasileira, 2008.

ORMEZZANO, L. Cultura, consumo e estereótipos: significações de estudantes do curso de educação artística. Famecos. Porto Alegre, Volume 1, Número 32, 118-125, 2007.

PÁDUA, E. Comunicação e espaço público. Comunicação, Mídia e Consumo. São Paulo, Volume 1, Número 2, 173-200, 2004.

PASÍN, E. Lo mediático y lo social: uma compleja interacción. Famecos. Porto Alegre, Volume 1, Número 32, 118-125, 2007.

PINHEIRO, M. C. Publicidade: a procura amorosa do consumo. Comunicação, Mídia e Consumo. São Paulo, Volume 3, Número 8, 168-187, 2006.

REGIS, F. Tecnologias de comunicação, entretenimento e competências cognitivas na cibercultura. Famecos. Porto Alegre, Volume 36, Número 3, 32-37, 2008.

RODRIGUES, M. C. C. As apropriações do conceito 'indústria cultural' nos estudos recentes de Comunicação no Brasil - uma análise a partir das principais revistas acadêmicas. Monografia de Conclusão de Curso. São Paulo, Faculdade Cásper Líbero, 2009.

RÜDIGER, F. Ciência social critica e pesquisa em comunicação. Vale dos Sinos, Ed. Unisinos, 2002.

RÜDIGER, F. Comunicação e indústria cultural: a fortuna da teoria crítica nos estudos de mídia brasileiros. Revista Intercom. São Paulo. Volume XXI, Número 1. Página 13-25. Julho/ Dezembro 1998.

RÜDIGER, F. Comunicação e teoria critica da sociedade. Porto Alegre, Ed. PUCRS, 1999. 
SAFATLE, V. Destruição e reconfiguração do corpo na publicidade mundial dos anos 90. Comunicação, Mídia e Consumo. São Paulo, Volume 1, Número 1, 17-32, 2004.

SCHNEIDER, M. A teoria do valor de Marx e a educação do gosto. Comunicação \& Educação, São Paulo, Ano 11, Número 2, Página 167-176, 2006.

SILVA, J. M. A política na TV de ficção. Comunicação, Mídia e Consumo. São Paulo, Volume 2, Número 3, 11-23, 2005.

SILVA, J. M. Interfaces: Michel Maffesoli, teórico da comunicação. Famecos, Porto Alegre, Volume 1, Número 25, 43-48, 2004.

SIQUEIRA, V. H., OLIVEIRA, C. \& BRAGA, J. O cinema e a formação docente: um diálogo sobre as questões de gênero. Comunicação e Educação, São Paulo, Ano 10, Número 2, Página 157-164, 2005.

TRIVINHO, E. A condição transpolítica da cibercultura. Famecos. Porto Alegre, Volume 1, Número 31, 70-78, 2006.

TRIVINHO, E. Alteridade, corpo e morte no cyberspace: cicatrizes de um hipercrime na epifania do virtual. Famecos, Porto Alegre, Volume 1, Número 23, 30-50, 2004.

TRIVINHO, E. Introdução à dromocracia cibercultural: contextualização sociodromológica da violência invisível da técnica e da civilização mediática avançada. Famecos, Porto Alegre, Volume 1, Número 28, 63-78, 2005.

TROTTA, Felipe. Juízos de valor e valor dos juízos: estratégias de valoração na prática do samba. Galáxia, São Paulo, Volume 7, Número 13, 115-127, 2007.

VOUGA, A. Os leilões virtuais e a dimensão cultural da formação do valor econômico. Comunicação, Mídia e Consumo. São Paulo, Volume 4, Número 11, 77-93, 2007.

Original recebido em: $21 / 11 / 2011$

Aceito para publicação em: 29/11/2011

Resumo sobre o autor

Luís Mauro Sá Martino é professor do Programa de Pós-Graduação em Comunicação da Faculdade Cásper Líbero. Autor dos livros "Teoria da Comunicação" e "Comunicação e 
Identidade", entre outros.

Maysa Ciarlariello Cunha

Rodrigues é jornalista, cientista

social e mestranda em Sociologia

na Universidade de São Paulo. 